\title{
Can commercial protection be good for research?
}

\author{
It's unscientific to let market forces dictate a change in the way science is carried out.
}

Sir - Ari Patrinos and Dan Drell (Nature

$417,589-590 ; 2002)$ recommend that

journals embrace the commercial

realities facing science, suggesting that

arrangements such as Science allowing

some data restriction are necessary for

progress. Although they accept that open

access to research data has been crucial to

scientific success, their core argument is

that too much data will remain locked in

the private sector unless journals become

more accommodating. Patrinos and

Drell's suggestion is that publicly funded

information should be unrestrictedly

available, whereas privately funded

findings can be legitimately restricted for

an agreed time.

Such reasoning may be the start of a slippery slope leading to different standards and treatment for privately funded, profit-making science. The growing trend towards public-private partnerships will grease the slope and stud it with inconsistencies. Will the public's share of data be embargoed with the private? Will the length of the embargo be determined by the ratio of public and private money? Will the time of data release be negotiated by authors with publishers on an individual basis? After all, offsetting the credit reward from early disclosure against the loss of privileged access to one's own data is as important to the career of a publicly funded scientist as to the profit of a corporation.

Even more general than these considerations is the role of data disclosure in scientific success. The tension between openness and protection of novel findings is a key feature in the dynamics of collective scientific practice. The way scientists have historically balanced competition and cooperation has led to generations of scientific achievement. More data may indeed be gained for all from special publication arrangements, but will this be sufficient compensation for the loss of a mechanism that has been crucial in the extraordinary accomplishments of many disciplines?
Both supporters of early, full data release and advocates of partial commercial protection argue that their strategy leads to more scientific progress. We agree with Patrinos and Drell that norms of 'free access' and 'total disclosure' are unrealistic: indeed, pre-publication secrecy has always been part of successful science. Nevertheless, accepting a trend of increasing market orientation as a policy guide is unscientific. How science works is itself a scientific question, not an ethical or pragmatic one. Surely, scientific inquiry should rule on the advisability of overthrowing conventions associated so strongly with scientific success. It is remarkable that the effects of radical changes in institutional settings and reward structures for scientists have not been more extensively researched.

Maureen. A. O'Malley, Andrew J. Roger, W. Ford Doolittle

Department of Biochemistry and Molecular Biology, Dalhousie University, Halifax,

Nova Scotia B3H 4H7, Canada

\section{Industry scientists look for benefits, not risks}

Sir - The Correspondence "Conflicts around a study of Mexican crops" (Nature 417, 897-898; 2002) was an excellent reminder to readers of what it means to be a scientist in a value-laden world. But surely nobody can be surprised that those involved in this controversy are accusing each other of conflicts of interest, or that indeed they have such conflicts?

I would not expect scientists in the genetic-modification industry to publish experiments showing whether genetically modified organisms pose a risk to the environment or human health, because their priorities are improvements and applications. The search for risk is therefore left to researchers who have some reason, whether ideological or any other, to hypothesize that there might be a risk.

What seemed to me the most important aspect of the Correspondence debate was not the possible conflicts of interest themselves, but the honesty of all the participants. Conflicts of interest by authors of publications can be handled by openly declaring them, yet the potential honesty of the authors is less easy to decipher. This is what we should worry about, because in order to survive as a profession we need to ensure that, in the words of your Opinion article
(Nature 418, 111; 2002): "trust in science remains deservedly high".

Maria J. Hötzel

LETA - Laboratory for Applied Ethology,

Departamento de Zootecnia e Desenvolvimento Rural, Universidade Federal de Santa Catarina, Rodovia Admar Gonzaga, 1346, Itacorubi, Florianópolis, SC 88.034-001, Brazil

\section{Public-access group supports PubMed Central}

Sir - Your News story "Public-access group plans journals" (Nature 418, 805; 2002) reported one of us (M.B.E.) as saying on behalf of the Public Library of Science (PLS) that PubMed Central is "woefully inadequate" in meeting researchers' needs. In fact, the PLS strongly supports PubMed Central (http://pubmedcentral.nih.gov/) and its laudable efforts to create a digital archive of the scientific literature that is freely accessible and fully searchable. What was criticized as "woefully inadequate" is not PubMed Central itself, but publishers' participation in it: since its founding in 1999, relatively few publishers have taken advantage of this opportunity to serve the scientific community better.

PLS (www.publiclibraryofscience.org) was formed nearly two years ago to show publishers that the scientific community supports PubMed Central and other free, full-text public libraries of scientific literature. Although it has received strong, broad-based support from scientists and the public, most publishers - including those of Nature - are, in our opinion, resisting the will of the scientific community and are the major obstacle to improving access to the literature. It is this failure, not any dissatisfaction with PubMed Central itself, that leads us to conclude that the scientific community will have to take the initiative to create new journals that enable immediate and unencumbered access to published reports through public resources.

It is not the case, as your News story states, that PLS withdrew its boycott. It continues to urge scientists to show their support for the principle of open access to the scientific literature by publishing exclusively in journals that make their content freely available through archives such as PubMed Central.

Michael B. Eisen ${ }^{\star}$, Patrick O. Brown $\dagger$, Harold E. Varmus

* Life Sciences Division, Lawrence Orlando Berkeley National Lab and Department of Molecular and Cell Biology, University of California,

1 Cyclotron Road, Berkeley, California 94720, USA $\dagger$ Department of Biochemistry and

Howard Hughes Medical Institutes, Stanford University School of Medicine, 300 Pasteur Drive, Stanford, California 94305, USA $\$$ Memorial Sloan Kettering Cancer Center, 1275 York Avenue, New York, New York 10021, USA 